\title{
Prevalence of Campylobacter spp. Isolated from Pigs in Three Slaughterhouses of Yaounde Cameroon
}

\author{
Serge Damase Oyong Assiene ${ }^{1 *}$, Esther Ngah², Roger Celestin Ayangma ${ }^{3}$, Dieudonné Ndjonka ${ }^{4}$ \\ ${ }^{1}$ Laboratory of Microbiology of Higher Institute of Medical Technology, Douala University, Douala, Cameroon \\ ${ }^{2}$ National Higher School of Agro-Industrial Sciences, Ngaoundere University, Ngaoundere Cameroon \\ ${ }^{3}$ Military Hospital of Yaounde, Higher Institute of Medical Technology, Douala University, Douala, Cameroon \\ ${ }^{4}$ Faculty of Sciences, Ngaoundere University, Ngaoundere, Cameroon \\ Email: `assienesergeo@yahoo.fr, hadassa.ngah@gmail.com, ceay2007@gmail.com,ndjonka_dede@yahoo.com
}

How to cite this paper: Oyong Assiene, S.D., Ngah, E., Ayangma, R.C. and Ndjonka, D. (2021) Prevalence of Campylobacter spp. Isolated from Pigs in Three Slaughterhouses of Yaounde Cameroon. Advances in Microbiology, 11, 213-224.

https://doi.org/10.4236/aim.2021.115016

Received: February 25, 2021

Accepted: May 9, 2021

Published: May 12, 2021

Copyright $\odot 2021$ by author(s) and Scientific Research Publishing Inc. This work is licensed under the Creative Commons Attribution International License (CC BY 4.0).

http://creativecommons.org/licenses/by/4.0/

\begin{abstract}
Enteric campylobacteriosis caused by Campylobacter is a real public health problem. It is a typical zoonosis that can be transmitted through direct contact with contaminated animals or animal carcasses, or indirectly through the ingestion of contaminated food or water. $\mathrm{WHO}^{1}$ defines Campylobacter as the first germ responsible for gastroenteritis in developing countries. The objective of the study is to determine the prevalence of Campylobacter in pigs and to identify the most common species found in three slaughterhouses in the city of Yaounde. A descriptive and prospective study was carried out over a period of five months, from July to November 2020. To do this, Campylobacter spp. strains were searched for by culture on specific media, incubated in a micro-aerophilic atmosphere at $37^{\circ} \mathrm{C}$ and the identification with API campy (BioMérieux, ref 20800). Out of the 266 samples collected, 170 from the rectum and 96 from the carcasses, we obtained a general prevalence of $27 \%$, with a prevalence of $25.88 \%$ in the rectum and $29.16 \%$ in the carcasses. Pigs intended for consumption by the population of Yaounde come mainly from the North (50\%) and the West (49\%). The most common species encountered were $C$. coli (52.77\%), C. jejuni spp. jejuni 1 and 2 (30.58\%), C. festus spp. festus (11.11\%), C. jejuni spp. doley (1.38\%), and Campylobacter spp. (4.16\%). Bacterial enumeration gave Campylobacter fecal concentrations at $10^{3} \mathrm{CFU}^{2}(52.7 \%), 10^{4} \mathrm{CFU}(33.3 \%)$, and $10^{5} \mathrm{CFU}$ (13.8\%). The slaughterhouse in the Mvog Ada market was the most involved in Campybacter cases, followed by the $8^{\text {th }}$ market and Essos market. From the above, it is important
\end{abstract}

World Health Organization.

${ }^{2}$ Colony Forming Unit. 
to notice that the Campylobacter danger remains and that preventive measures are of great interest.

\section{Keywords}

Campylobater, Zoonosis, Pigs, Prevalence

\section{Introduction}

The presence of infectious pathogens and toxins in animal populations and products of animal origin is a considerable and permanent threat to health. $60 \%$ of existing human diseases are of zoonotic origin and $75 \%$ of emerging human infectious pathogens are of animal origin [1].

Enteric Campylobacteriosis is a typical zoonosis that can be transmitted through direct contact with animals or animal carcasses, or indirectly through the ingestion of contaminated food or water. Campylobacter are enteric commensals or occasional pathogens in a wide range of animals and are thus the source of infections in humans [2]. Campylobacter is a bacterium comprising about 15 species, the most isolated of which are $C$. jejuni, C. coli and C. festus. Enteric campylobacteriosis is an intestinal infection almost always caused by $C$. jejuni or $C$. coli in the form of diarrhea; $C$. festus can cause neonatal infection [3]. Wild, farm and domestic animals and birds are reservoirs of infection. Amongst animals carrying the Campylobacter that can transmit the disease to humans, pigs have $0.4 \%$ Campylobacteriosis due to C. jejuni [4]. However, with C. coli, which is more prevalent in pigs, this percentage increases to $4.4 \%-6 \%$ [4] [5]. As several studies have indicated, pigs are considered to be a less important reservoir for Campylobacteriosis as compared with poultry. There are few initiatives to control Campylobacter in pig slaughter processes.

Studies on the prevalence of Campylobacter in pigs isolated from rectal samples from slaughterhouses have shown approximately $38.1 \%$ to $63 \%$ Campylobacter carriage [6] [7] [8]. The concentration of Campylobacter in pig faeces ranges up to $1.2 \times 10^{7} \mathrm{CFU} / \mathrm{g}$ [9]. Campylobacter colonization is asymptomatic. Several studies show that more than $90 \%$ of Campylobacter isolated from pig faeces are $C$. coli and then $C$. jejuni [10]. Nevertheless, $C$. jejuni may be predominant; this was the case of [7] in his study where he recorded a predominance of $C$. jejuni. According to surveys conducted by EFSA and ECDC, it appears that in 2014, 6\% - 37\% of Campylobacter are found in pig carcasses in Belgium and Poland respectively [11].

Enteric campylobacteriosis remains a real public health problem. In Cameroon, the spread and asymptomatic carriage of this germ in animals is poorly known, particularly in pigs. The objective of this study is to highlight the prevalence of carrier of this germ in pigs in the slaughterhouses of the city of Yaounde Cameroon, in order to highlight the potential risk to butchers, retailers and consumers. 


\section{Methodology}

\subsection{Ethical Approval}

For this study, ethical clearance was obtained by the National Committee on Research Ethics for Human Health. Research authorisation was also granted by the Ministry of Scientific Research and Innovation, and by the departmental delegation of the Ministry of Livestock, Fisheries and Animal Industries.

\subsection{Biological Materials}

The biological material is the pig, consisting mainly of the rectal parts and the carcass after evisceration of the slaughtered pigs. The collection was carried out in three slaughterhouses in the city of Yaounde (Mvog Ada market, $8^{\text {th }}$ market, and Essos market).

\subsection{Sampling Plan}

The samples were taken from two parts of the pig, the rectum and the carcass after evisceration using the swabs (Photo 1). The samples were taken on market days when there was a high slaughter rate. The swabs were introduced into modified Preston broth [12] contained in cryotubes. They were then stored for transport in a cooler containing cold accumulators. Maintained at $\pm 4^{\circ} \mathrm{C}$. The samples were sent to the laboratory for analysis.

\subsection{Methods}

A descriptive and prospective study was carried out over a period of five months, from July to November 2020 in the 03 logging sites in the city of Yaounde. We carried out a quota sampling based on the number of pigs slaughtered in the various slaughterhouses. Only the pigs coming from the different pigsties intended for slaughter were selected. All pigs arriving smothered or sick at the slaughterhouses were excluded from the study. Once the samples were taken, they were sent to the laboratory and culture was carried out on modified cefoperazone deoxycholate charcoal specific media (Photo 2). Incubation took place in microaerophilic conditions at $37^{\circ} \mathrm{C}$, and the boxes were read 48 to 72 hours.

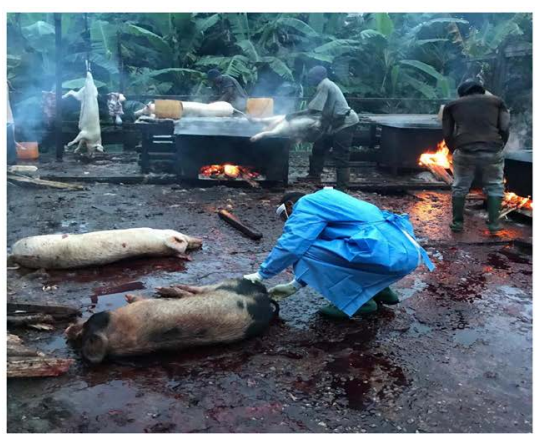

(a)

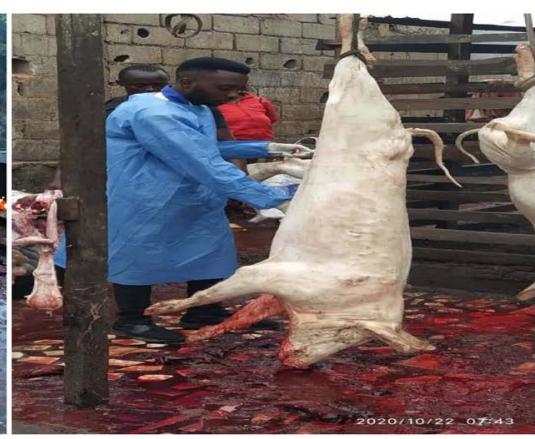

(b)

Photo 1. Collection of biological samples (a) Pig's anus; (b) Carcasses after evisceration. Source: This study. 


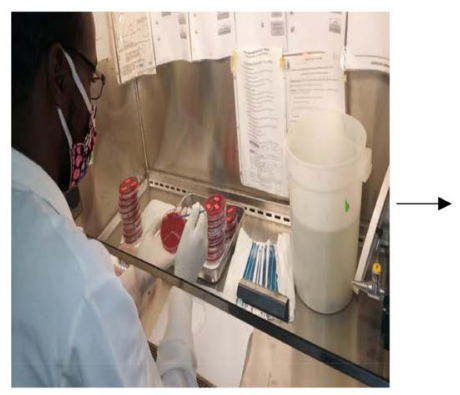

(a)

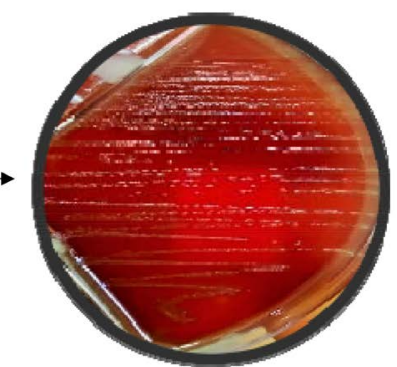

(b)

Photo 2. Isolation of Campylobacter spp. (a) Inoculation under a class 2 safety cabinet (b) Campylobacter spp. colonies on fresh blood agar. Source: Present study.

On the positive cultures we performed Gram and fresh state to visualize and confirm the bacterial morphology of Campylobacter spp. catalase and oxidase tests were also performed. All catalase and oxidase positive colonies were confirmed on API Campy (BioMérieux, ref 20800). The API campy strip consists of 20 microtubes containing dehydrated substrates. It is made up of two parts. The first part of the strip (enzymatic and conventional tests) is inoculated with a dense suspension which rehydrates the substrates. During incubation (in aerobic conditions), metabolism produces color changes that are either spontaneous or revealed by the addition of reagents. The second part of the strip (assimilation or inhibition tests) is inoculates with a minimal medium and incubated in microaerophilic conditions. The bacteria grow if they are capable of utilizing the corresponding substrate or if they are resistant to the antibiotic tested. The identification is obtained by the identification software.

We then performed a bacterial enumeration on the positive samples in order to have the bacterial load in $1 \mathrm{~g}$ of faeces. To do this we applied the Most Probable Number (MPN) technique combined with the $10 \mu \mathrm{l}$ calibrated oese technique. This method is a statistical estimate of number of microorganisms supposed to be distributed in our liquid sample in a perfectly random manner. The estimate of the obtained by applying the principle of likelihood, from positive responses observed for one or more successive dilutions of the original bacterial suspension. We made 5 dilutions from $10^{-1}$ to $10^{-5}$. If there is at least one microorganism in $1 \mathrm{ml}$ of the $10^{-3}$ dilution and less than one microorganism in $1 \mathrm{ml}$ of the $10^{-4}$ dilution and therefore we can deduce that there is at least $10^{3}$ microorganisms but less than $10^{4}$ microorganisms in $1 \mathrm{ml}$ of pure product. The calibrated loop technique is very useful in the enumeration of urinary germs. We applied it to the samples of carcasses inoculated on Campylobacter spp. it consists in carrying out a seeding by exhaustion using the quadrants with a loop handle calibrated at $10 \mu$ l. the $1^{\text {st }}$ quadrant corresponds to $10^{3} \mathrm{CFU}$ when there is microbial growth. Thus the $2^{\text {nd }}, 3^{\text {rd }}$ quadrants correspond successively to $10^{4} \mathrm{CFU}$ and $10^{5}$ CFU.

The data obtained were introduced into the Excel 2013 spreadsheets. We thus applied a descriptive statistic with the different variables. This allowed us to generate tables, calculations and histograms/pie charts. 


\section{Results}

The study allowed us to collect and analyse samples of pig rectums and carcasses. The variables selected were the origin of the pigs, slaughter sites, germs, and bacterial count. The results obtained are reported as follows:

\subsection{Summaries of the Samples Collected}

A total of 266 samples were taken. 170 pigs anus samples; 96 pigs carcass samples. The pigs samples taken are summarised in Table 1 . Out of a total of 440 pigs slaughtered during our collection, $45.4 \%$ came from the $8^{\text {th }}$ market slaughterhouse and $45.4 \%$ from the Mvog Ada Market slaughterhouse. On the other hand we have $9.1 \%$ from the Essos market slaughterhouse, which shows that the Mvog Ada slaughterhouse and the $8^{\text {th }}$ market slaughterhouse are the ones that slaughter the most pigs.

\section{Origin of the pigs in the different slaughter sites}

Pigs brought for slaughter come from many different sources. Figure 1 shows the different regions and city of origin. The Western and Northern regions raise and supply more pork to the country for slaughter and consumption. On the other hand, the Essos market slaughterhouse is more concerned with pigs coming from pig farms in the city of Yaounde. The slaughterhouses in Mvog Ada and $8^{\text {th }}$ are more concentrated in the western and northern regions.

Out of the 170 pigs collected in the various slaughterhouses, 81 were collected at the $8^{\text {th }}$ market, 69 at the Mvog-ada market and 20 at the Essos market. The origin of pigs for the various slaughterhouses reveals that: at the $8^{\text {th }}$ market $48.14 \%$ (39/81) came from the West, 49.38\% (40/81) came from the North and $2.46 \%(2 / 81)$ came from Yaounde. At the Mvog-ada market $49.27 \%$ (34/69) came from the West and 50.72\% (35/69) came from the North; while at Essos market $100 \%(20 / 20)$ came from pigsties in the city of Yaounde.

\subsection{Bacteriological Analyses}

\section{Prevalence of isolated Campylobacter spp.}

Campylobacter spp. isolated after culture and identification are shown in Figure 2 . The resulting prevalence is $27 \%(72 / 266)$. The frequency of negativity is $73 \%(194 / 266)$.

Table 1. Summary of samples collected from the different slaughter sites.

\begin{tabular}{ccccc}
\hline & \multicolumn{3}{c}{ Number of samples per swab type } \\
\hline Slaughterhouse & Slaughter flow & Sample of the Rectum & Carcasses after evisceration & Total \\
\hline & $\mathrm{N}(\%)$ & & & $\mathrm{N}(\%)$ \\
$\mathbf{8}^{\text {th }}$ Market & $200(45.4)$ & 80 & 40 & $120(45.1)$ \\
Mvog Ada Market & $200(45.4)$ & 70 & 40 & $110(41.3)$ \\
Essos Market & $40(9.1)$ & 20 & 16 & $36(13.5)$ \\
Totals & 440 & 170 & 96 & $266(51.3)$ \\
\hline
\end{tabular}




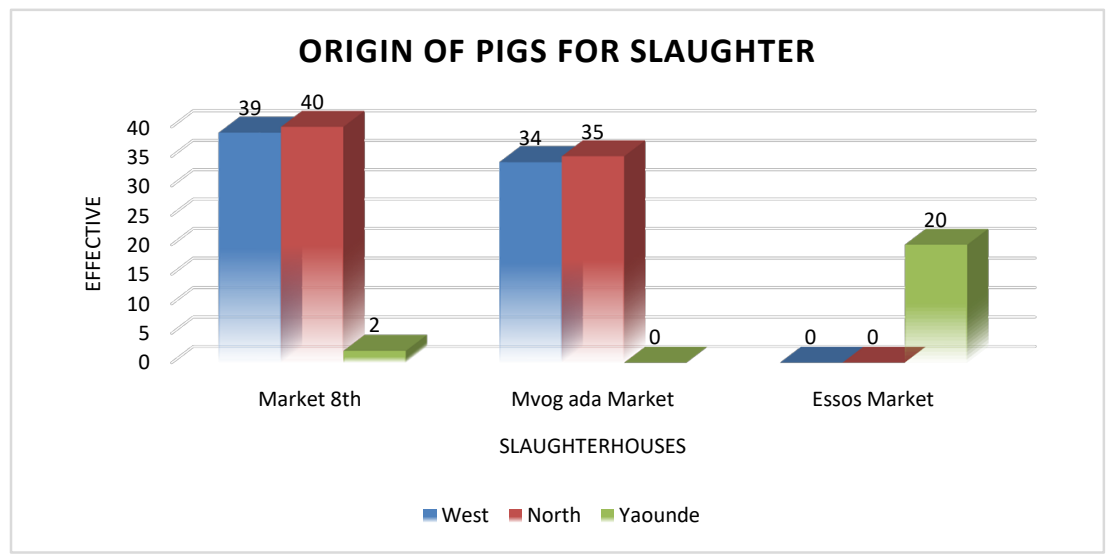

Figure 1. Origin of pigs for slaughter according to the different slaughterhouses.

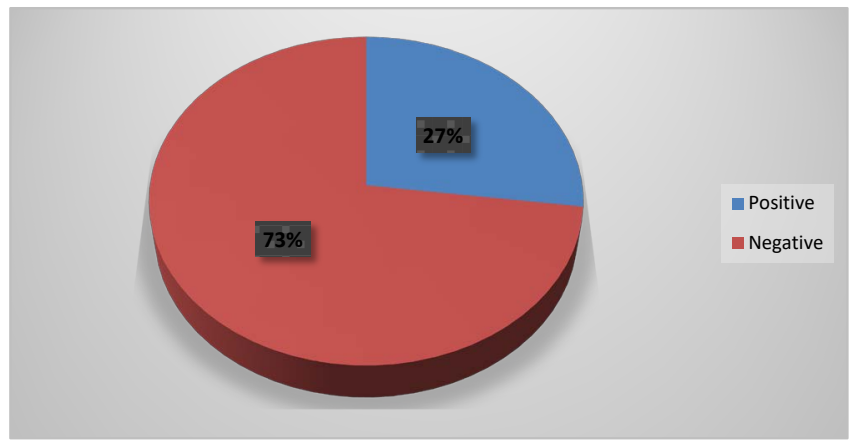

Figure 2. Prevalence of Campylobacter spp. in the study population.

27\% represents the overall prevalence of Campylobacter isolated in our study. The prevalence of Campylobacter isolated from the rectum is $\mathbf{2 5 . 8 8 \% ~ ( 4 4 / 1 7 0 )}$ and those isolated from carcasses is $29.16 \%$ (28/96).

\section{$>$ Campylobacter species encountered in the study}

During our analysis we isolated several species of Campylobacter, mainly $C$. coli, $C$. jejuni and $C$. festus. Figure 3 shows the different species encountered.

The identification of the Campylobacter species allowed us to obtain Campylobacter coli at 52.77\% followed by Campylobacter jejuni 1 and 2 at 30.58\% (12.50\% $+18.08 \%$ ). Campylobacter festus spp. festus was found at $11.11 \%$ and Campylobacter spp. at $4.16 \%$ due to some identification difficulties linked to the supply disruption in the API Campy gallery. Campylobacter coli was thus the most encountered species with a difference of $22 \%$ compared to Campylobacter jejuni.

\section{$>$ Isolated species according to slaughter sites and microbial enumeration}

The identification by the API Campy gallery allowed us to highlight the different species encountered. Table 2 shows the different proportions of isolated species according to the slaughter sites and swabbing areas. Also the microbial count of the positive samples.

It emerges that the Mvog Ada site has more germs 50\% $(22+14=36 / 72)$, followed by the $8^{\text {th }}$ market $38.88 \%(16+12=28 / 72)$ and the Essos market $11.11 \%$ $(6+2=8 / 72)$. The bacterial count shows that the germ concentration was found at $10^{3} \mathrm{CFU} 52.7 \%, 10^{4} \mathrm{CFU} 33.3 \%$ and $10^{5} \mathrm{CFU} 13.8 \%$. 
Table 2. Campylobacter according to sampling areas and slaughter site plus enumeration.

\begin{tabular}{|c|c|c|c|c|c|c|c|c|c|}
\hline \multirow[b]{2}{*}{ Germs/species } & \multicolumn{2}{|c|}{ Mvog Ada } & \multicolumn{2}{|c|}{$8^{\text {th }}$} & \multicolumn{2}{|c|}{ Essos } & \multicolumn{3}{|c|}{ Microbial growth/CFU } \\
\hline & Rectum & Carcasses & Rectum & Carcasses & Rectum & Carcasses & $10^{3}$ & $10^{4}$ & $10^{5}$ \\
\hline C. coli & $12(54.5 \%)$ & $08(57.1 \%)$ & $09(56.25)$ & $06(50 \%)$ & $03(50 \%)$ & l & 20 & 13 & 05 \\
\hline C. jejuni spp. jejuni 1 & $02(9.1 \%)$ & $01(7.1 \%)$ & $03(18.7)$ & $01(8.3)$ & $02(33.3 \%)$ & I & 03 & 05 & 01 \\
\hline C. jejuni spp. jejuni 2 & $04(18.1)$ & $03(21.4 \%)$ & $01(6.2 \%)$ & $03(25 \%)$ & $01(16.6 \%)$ & $01(50 \%)$ & 09 & 02 & 02 \\
\hline C. jejuni spp. doley & l & l & l & l & I & $01(50 \%)$ & 01 & l & l \\
\hline C. festus spp. festus & $04(18.1 \%)$ & $02(14.2 \%)$ & $01(6.2 \%)$ & $01(8.3 \%)$ & I & I & 04 & 02 & 02 \\
\hline Campylobacter spp. & l & I & $02(12.5 \%)$ & $01(8.3 \%)$ & I & I & 01 & 02 & I \\
\hline Totals & 22 & 14 & 16 & 12 & 06 & 02 & 38 (52.7\%) & $24(33.3 \%)$ & $10(13.8 \%)$ \\
\hline
\end{tabular}

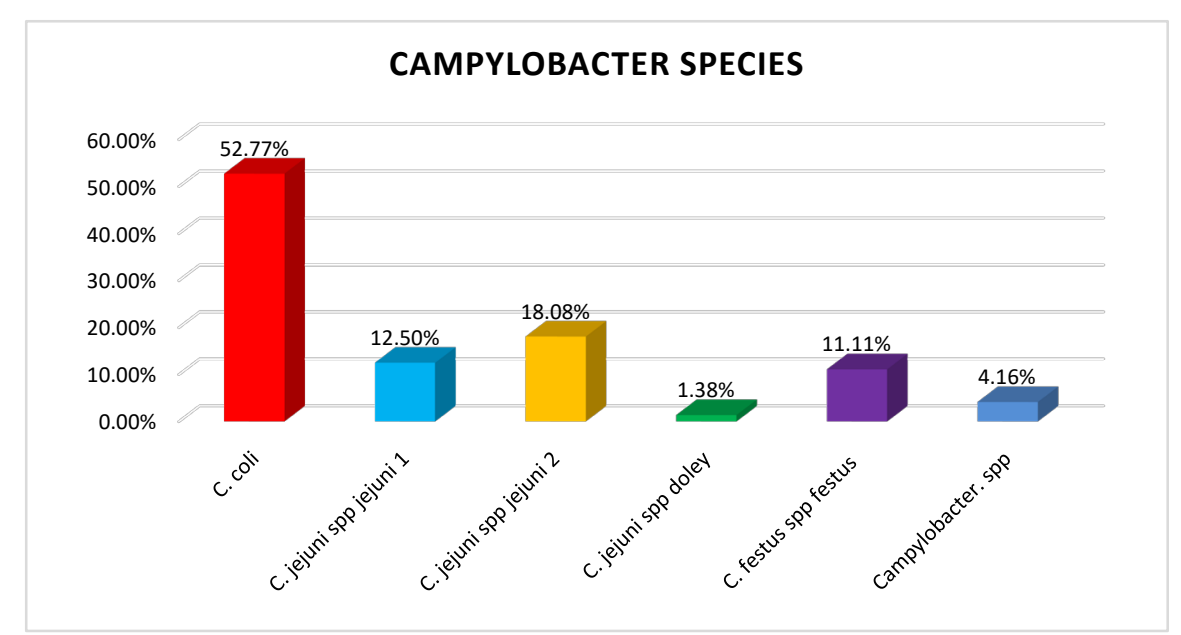

Figure 3. Different species of Campylobacter isolated in the study.

\section{Discussion}

The high flow of slaughter respectively (45.5\%; 45.5\%) observed at the Mvog Ada and $8^{\text {th }}$ market sites reveals that these two sites are the primary pig producing areas of the artisanal slaughterhouse in Yaounde city, intended for consumption, as compared to the slaughter flow at the Essos market which has a low rate (9.1\%). This is due to the fact that the slaughter sites of Mvog Ada and eighth are the oldest in the city of Yaounde in the process of slaughtering pigs. On the other hand, pig slaughter has an illicit circuit which is not controlled by the veterinary services of the districts of the Ministry of Livestock, Fisheries and Animal Industries (MINEPIA). In the city of Yaounde of the year 2020, the slaughter sites recognised by the departmental delegation of MINEPIA are the $8^{\text {th }}$ market slaughterhouse, the Mvog Ada market slaughterhouse and the Essos market slaughterhouse.

The Far North (Adamaoua, North, and Far North) and Western regions remain the two areas with the highest percentage of pig production. These are areas where livestock farming is part of the cultures of the people who live there. 
In the history of livestock farming in Cameroon, it was the domain of predilection of the non-Islamic populations of the south of the country. Since 1970, the great South (Centre, South, West, Littoral, North-West and South-West regions) alone possesses about $98 \%$ of the national livestock. Following the African Swine Fever in 1982 in the southern part of the country and the doubling of input prices due to the devaluation of the CFA franc in 1994, livestock farms in the south of the country suffered huge losses [13]. As a result, production has fallen increasingly over the years, due to the plague which has become endemic. On the other hand, livestock farming in the far north, which has not been affected by this epidemic, is therefore booming. Thus the pork industry in the north is characterised by low production costs due to extensive breeding. The pork of the northern sector is thus characterized by the appellation "pork of the North" because it is low fat and follows a mode of consumption of pork meat in Cameroon the "embers".

Our study shows that the general prevalence of Campylobacter is 27\%, with $25.88 \%$ in the rectum and $29.16 \%$ in the carcasses. The prevalence of Campylobacter in the pig industry varies according to the country, the conditions of the farms and the slaughter of the pig. In Poland a survey on pork meat gave a prevalence of $12.6 \%$ [14]; in Ghana (Kumasi) a survey on pig carcass gave a prevalence of $36.3 \%$ [15]; in Ivory Coast a survey on pig faeces gave a prevalence of $1.1 \%$ [16]; and in France a survey on pig faeces gave a prevalence of $14.8 \%$ [17]. Another study in 10 States of United States on pig faeces gave a prevalence of $56.3 \%$ [18]; another study in the US on pig faeces associated with diarrhoea gave a prevalence of $82.6 \%$ [19]. This variation in prevalence clearly shows that Campylobacteriosis in the pig sector takes into account several parameters such as the presence or absence of diarrhoea in pigs selected for study, the different types of sampling, the methods of breeding, slaughter, hygiene and sanitation. On the other hand, isolation techniques are also a parameter to be taken into consideration; molecular techniques remain better than biochemical techniques. In the case of our study, we limited ourselves to biochemical techniques due to the high cost of molecular techniques and the scarcity of technical platforms with the necessary equipment for carrying out molecular techniques.

The Campylobacter species encountered showed a predominance of $C$. coli (52.77\%) followed by $C$. jejuni spp. jejuni 1 and 2 (30.58\%), C. festus spp. festus (11.11\%), Campylobacter spp. (4.16\%) and C. jejuni spp. doley (1.38\%). As reported in several studies and the literature $C$. coli is the most common species found in pigs. Our results are in line with the literature and some works that have found $C$. coli at $99 \%$ in pig faeces [10] [20] [21]. The prevalence of $C$. jeju$n i$, which comes second, shows the competitiveness that always exists between the two species depending on the animal. $C$. jejuni is more prevalent in poultry, in the framework of our study there is a real crossbreeding between chicken and pigs in the different slaughter sites. In these slaughter sites there are areas where chickens are killed and cleaned, and we get our supplies from the same water 
source for cleaning the pigs. This makes it highly likely that Campylobacter will cross between chickens and pigs. [22] in their study which aimed to show the variation of $C$. coli and $C$. jejuni in the intestinal colonisation of organically reared pigs never obtained $C$. jejuni superior to $C$. coli. $C$. jejuni has always been in second place; so our results agree with theirs [10] [22]. Human Enteric Campylobacteriosis is more caused by $C$. jejuni and C. coli. However, we also have other species involved in Campylobacteriosis in animals, such as $C$. festus, which causes systemic abortions and infections; we have isolated it at a percentage of $11.11 \%[3]$.

In the different slaughter sites (Mvog Ada, $8^{\text {th }}$, Essos) we recorded Campylobacter with a bacterial count that predominated at $10^{3}$ UFC $52.7 \%$ (38/72) followed by $10^{4}$ UFC $33.3 \%$ (24/72) and $10^{5}$ UFC $13.8 \%$ (10/72). Our results show that the microbial density of Campylabacter is not very high in the digestive tract and carcasses of pigs. All pigs excrete Campylobacter in the faeces in the range of $8-13$ weeks of age in the proportion of $10^{3}-10^{7} \mathrm{CFU} / \mathrm{g}$ faeces. For a long time Campylobacter has always been found in the gut of pigs in $50 \%$ to $100 \%$ with the proportions of $10^{2}-10^{7} \mathrm{CFU} / g$ stool [21] [23]. The Mvog Ada market slaughter site is the site where we encountered the most Campylobacter $50 \%$ (36/72), followed by the $8^{\text {th }}$ market slaughterhouse $38.88 \%(28 / 72)$ and the Essos market slaughterhouse $11.11 \%$ (8/72). The predominance of the Mvog Ada market slaughterhouse could be explained by the high level of activity on this site, and also by the crossbreeding between the different animals that are killed in the vicinity of the market.

\section{Conclusion}

Campylobacteriosis remains a public health problem due to repeated gastroenteritis and the diagnosis is not always properly made because of the cost and complexity. The objective of our study was to determine the prevalence of Campylobacter spp. in pigs in order to prevent or assess the risk to consumer populations and workers in the pork industry. The general prevalence of $27 \%$, of which $25.88 \%$ in the rectum and $29.16 \%$ in the carcasses obtained, makes it clear that the Campylobacter danger exists and preventive measures should be implemented. To make butchers and retailers aware of the Campylobacter risk, they should scrupulously respect hygiene measures to prevent the spread of the germ. To this end, it would be advisable for the veterinary services of the MINEPIA delegations to make sure that butchers wear protective equipment and that chemical agents are always present to sanitise the work areas and also for thorough cleaning after the work is completed. On the other hand, it is essential to establish microbiological control in order to considerably reduce the risk of Campylobacter, which is considered by the WHO to be the first germ responsible for gastroenteritis in developing countries. Studies such as this one should be promoted in order to have as much data as possible to better control the spread of the germ. 


\section{Conflicts of Interest}

The authors declare no conflicts of interest regarding the publication of this paper.

\section{References}

[1] Organisation Mondiale de la Santé Animale (2013) le concept "Une sante" l'approche de l'OIE. Bulletin No. 2013-1.

[2] Whiley, H., van den Akker, B., Giglio, S. and Bentham, R. (2013) The Role of Environmental Reservoirs in Human Campylobacteriosis. International Journal of Environmental Research and Public Health, 10, 5886-5907. https://doi.org/10.3390/ijerph10115886

[3] Elbrissi, A., Sabeil, Y.A., Khalifa, K.A., Enan, K., Khair, O.M. and El Hussein, A.M. (2017) Isolation, Identification and Dierentiation of Campylobacter spp. Using Multiplex PCR Assay from Goats in Khartoum State, Sudan. Tropical Animal Health and Production, 49, 575-581. https://doi.org/10.1007/s11250-017-1231-x

[4] Mossong, J., Mughini-Gras, L., Penny, C., Devaux, A., Olinger, C., Losch, S., Cauchie, H.-M., van Pelt, W. and Ragimbeau, C. (2016) Human Campylobacteriosis in Luxembourg, 2010-2013: A Case-Control Study Combined with Multilocus Sequence Typing for Source Attribution and Risk Factor Analysis. Scientific Reports, 6, Article No. 20939. https://doi.org/10.1038/srep20939

[5] Sheppard, S.K., Dallas, J.F., Strachan, N.J.C., MacRae, M., McCarthy, N.D., Wilson, D.J., Gormley, F.J., Falush, D., Ogden, I.D., Maiden, M.C.J. and Forbes, K.J. (2009) Campylobacter Genotyping to Determine the Source of Human Infection. Clinical Infectious Diseases, 48, 1072-1078. https://doi.org/10.1086/597402

[6] Nathues, C., Grüning, P., Fruth, A., Verspohl, J., Blaha, T., Kreienbrock, L. and Merle, R. (2013) Campylobacter spp., Yersinia enterocolitica, and Salmonella enterica and Their Simultaneous Occurrence in German Fattening Pig Herds and Their Environment. Journal of Food Protection, 76, 1704-1711. https://doi.org/10.4315/0362-028X.JFP-13-076

[7] Carrique-Mas, J.J., Bryant, J.E., Cuong, N.V., Hoang, N.V.M., Campbell, J., Hoang, N.V., Dung, T.T.N., Duy, D.T., Hoa, N.T., Thompson, C., Hien, V.V., Phat, V.V., Farrar, J. and Baker, S. (2014) An Epidemiological Investigation of Campylobacter in Pig and Poultry Farms in the Mekong Delta of Vietnam. Epidemiology \& Infection, 142, 1425-1436. https://doi.org/10.1017/S0950268813002410

[8] Milnes, A.S., Stewart, I., Clifton-Hadley, F.A., Davies, R.H., Newell, D.G., Sayers, A.R., Cheasty, T., Cassar, C., Ridley, A., Cook, A.J.C., Evans, S.J., Teale, C.J., Smith, R.P., McNally, A., Toszeghy, M., Futter, R., Kay, A. and Paiba, G.A. (2008) Intestinal Carriage of Verocytotoxigenic Escherichia coli O157, Salmonella, Thermophilic Campylobacter and Yersinia enterocolitica, in Cattle, Sheep and Pigs at Slaughter in Great Britain during 2003. Epidemiology \& Infection, 136, 739-751.

https://doi.org/10.1017/S0950268807009223

[9] Abley, M.J., Wittum, T.E., Funk, J.A. and Gebreyes, W.A. (2012) Antimicrobial Susceptibility, Pulsed-Field Gel Electrophoresis, and Multi-Locus Sequence Typing of Campylobacter coli in Swine before, during, and after the Slaughter Process. Foodborne Pathogens and Disease, 9, 506-512. https://doi.org/10.1089/fpd.2011.1053

[10] Quintana-Hayashi, M.P. and Thakur, S. (2012) Longitudinal Study of the Persistence of Antimicrobial-Resistant Campylobacter Strains in Distinct Swine Production Sys- 
tems on Farms, at Slaughter, and in the Environment. Applied and Environmental Microbiology, 78, 2698-2705. https://doi.org/10.1128/AEM.07723-11

[11] EFSA (European Food Safety Authority) and ECDC (European Centre for Disease Prevention and Control) (2015) The European Union Summary Report on Trends and Sources of Zoonoses, Zoonotic Agents and Food-Borne Outbreaks in 2014. EFSA Journal, 13, Article No. 4329. https://doi.org/10.2903/j.efsa.2015.4329

[12] Bolton, F.J., Coated, D., Hinchliffe, P.M. and Robertson, L. (1983) Comparison of Selective Media for Isolation of Campylobacter jejunil coli. Journal of Clinical Pathology, 36, 78-83. https://doi.org/10.1136/jcp.36.1.78

[13] Joséphine, E.A.M., Uwizeyimana, L. and Sans, P. (2006) “ESSOR” “Espaces, Sociétés rurales et Logiques économiques” filière porcine camerounaise: Une compétitivité à l'épreuve de dysfonctionnements. Mémoire de master 2 recherche en géographie et aménagement.

[14] Andrzejewska, M., Szczepańska, B., Spica, D. and Klawe, J.J. (2019) Prevalence, Virulence, and Antimicrobial Resistance of Campylobacter spp. in Raw Milk, Beef, and Pork Meat in Northern Poland. Foods, 8, Article No. 420. https://doi.org/10.3390/foods8090420

[15] Karikari, A.B., Obiri-Danso, K., Frimpong, E.H. and Krogfelt, K.A. (2017) Antibiotic Resistance of Campylobacter Recovered from Faeces and Carcasses of Healthy Livestock. BioMed Research International, 2017, Article ID: 4091856. https://doi.org/10.1155/2017/4091856

[16] Koffi, K.E., Coulibaly, K.J., Saraka, N.D., Senin, C.B.V., Boka, H. and Dosso, M. (2020) Évaluation de la qualité microbiologique des carcasses de porcs abattus à la SIVAC: recherche de Salmonella, Yersinia et Campylobacter. Afrique Science, 16, 30-38. http://www.afriquescience.net

[17] Denis, M., Chidaine, B., Laisney, M.-J., Kempf, I., Rivoal, K., Mégraud, F. and Fravalo, P. (2009) Comparison of Genetic Profiles of Campylobacter Strains Isolated from Poultry, Pig and Campylobacter Human Infections in Brittany, France. Pathologie Biologie, 57, 23-29. https://doi.org/10.1016/j.patbio.2008.04.007

[18] Tadesse, D.A., Wittum, T., Bahnson, P.B., DeGraves, F., Funk, J.A., Thakur, S., Rajala-Schultz, P., Morgan Morrow, W.E. and Gebreyes, W.A. (2011) Prevalence and Antimicrobial Resistance Profile of Campylobacter spp. Isolated from Conventional and Antimicrobial-Free Swine Production Systems from Different U.S. Regions. Foodborne Pathogens and Disease, 8, 367-374. https://doi.org/10.1089/fpd.2010.0665

[19] Burrough, E., Terhorst, S., Sahin, O. and Zhang, Q. (2013) Prevalence of Campylobacter spp. Relative to Other Enteric Pathogens in Grow-Finish Pigs with Diarrhea. Anaerobe, 22, 111-114. https://doi.org/10.1016/j.anaerobe.2013.06.004

[20] Thakur, S. and Gebreyes, W.A. (2005) Prevalence and Antimicrobial Resistance of Campylobacter in Antimicrobial-Free and Conventional Pig Production Systems. Journal of Food Protection, 68, 2402-2410. https://doi.org/10.4315/0362-028X-68.11.2402

[21] Alter, T., Gaull, F., Kasimir, S., Gurtler, M., Mielke, H., Linnebur, M., et al. (2005) Prevalences and Transmission Routs of Campylobacter spp. Strains within Multiple Pig Farms. Veterinary Microbiology, 108, 251-261.

https://doi.org/10.1016/j.vetmic.2005.03.004

[22] Jensen, A.N., Dalsgaard, A., Baggesen, D.L. and Nielsen, E.M. (2006) The Occurrence and Characterization of Campylobacter jejuni and C. coli in Organic Pigs and Their Outdoor Environment. Veterinary Microbiology, 116, 96-105. 
https://doi.org/10.1016/j.vetmic.2006.03.006

[23] Niesen, E.M., Engberg, J. and Madsen, M. (1997) Distribution of Serotypes of Campylobacter jejuni and C. coli from Danish Patients, Poultry, Cattle and Swine. FEMS Immunology \& Medical Microbiology, 19, 47-56.

https://doi.org/10.1111/j.1574-695X.1997.tb01071.x 